\title{
MODELING OF THE TRAINING PREPARATION OF HIGHLY QUALIFIED FEMALE HOCKEY PLAYERS
}

\author{
Igor Shishkov
}

Moscow State Academy of Physical Culture, ORCID (D)

Russian Federation \& Belarusian State University of Physical Culture, Belarus

Igor Shishkov https://orcid.org/0000-0002-8831-6434

\begin{abstract}
The article is devoted to the study of effectiveness of building training and competitive loads of women's national team of the Republic of Belarus for the European Indoor Hockey Championship (Indoor Hockey). The study was conducted at a separate, three-month stage of the annual training cycle.

The Purpose of the study: To find optimal ratio between training and competitive loads using block training system for highly qualified hockey players. To achieve the goal, the following Tasks were set: 1. To determine the structure of training of Belarus national hockey players in clubs and during the training camps of the national team before the European Championship; 2. To evaluate training and competitive process as two separate areas of training for highly qualified hockey players; 3. To identify necessary volume and evaluate effectiveness of the use of non-specific loads of anaerobic orientation in shock microcycles during training process of hockey players and final result. Research hypothesis: it was assumed that control and test games, as well as non-specific loads of anaerobic orientation in shock microcycles, may have a positive effect on the efficiency of using block system for preparing highly qualified hockey players for a short-term tournament.

An analysis of the training structure of the women's national team of the Republic of Belarus is presented from the perspective of the modern block system of periodization. Thus, it can be stated that the polycyclic principle of building the training process in Indoor hockey game sport is approved today. The obtained data on the structure of training of hockey players can be used as model characteristics.
\end{abstract}

Key words: athlete monitoring, indoor hockey, international competition, periodisation, training construction model

\section{INTRODUCTION}

Training process modeling is one of the promising areas in modern top sports (Verkhoshansky, 1985; Issurin, 2019; Kostyukevich, 2011; Antonov, 2014a; Antonov, 2014b). It is closely connected with training process building and its periodization.

An extensive experience in the training process building of highly qualified athletes has been gained in sports practice (Kostukevich,
2011; Issurin, 2019; Antonov, 2014a; Lythe, 2008); Perrotta, Held \& Warburton, 2017; Kellya, Strudwicka, Atkinsonc, Drustb \& Gregson, 2020). To date, more serious studies have been carried out in cyclic sports, where the structure of the sport itself allows a precise approach to research, planning and control (Bondarchuk, 1986; Antonov, 2014b; Chavdarov, Antonov, 2017; Issurin, 2012; Touretski, 1998). Acyclic sports, and sport's games are somewhat aloof 
and less studied in this regard (Zelentsov, 1985).

The traditional periodization system of sports training has undergone evolutionary reform. Research in cyclic sports by Verkhoshansky (1985), Issurin (2008), Bondarchuk (1986), Turetsky (1993) has shown the effectiveness of the so-called block periodization, based on the use of highly concentrated loads, aiming at increasing the level of individual motor abilities (Bondarchuk, 1986; Verkhoshansky, 1985; Godik, 1980). In game sports, the innovators in this direction were A. Zelentsov and V. Lobanovsky (1985), whose block principle of building the training process contributed to the achievement of the first high sports results in football (Zelentsov, 1985), including the victory of Dynamo Kyiv in the Cup of Cups and in the Super cup of European Championships.

Our research focuses on field hockey, an Olympic sport with more than a century of history, and its discipline - Indoor Hockey. Field hockey, as a historical game sport, has become the prototype of all the existing types of hockey such as ice hockey, bandy, floorball, roller hockey, beach hockey, outdoor \& indoor hockey.

Given the successful performance of hockey players of the national team of the Republic of Belarus at the Indoor hockey European Championship 2020 in Minsk and their gold medals, we can confidently consider the process of preparation for the continental championship as a model.

ORGANIZATION OF THE RESEARCH

The studies were conducted on the basis of the women's national team of the Republic of Belarus on Indoor hockey and the Minsk Hockey Club team. The author of the article was directly involved in planning and organizing the training of the team. We analyzed training and competitive loads throughout the study period. The components of the training loads were recorded by the coaching staff of the teams. The training period under consideration was from October
28, 2019 to January 26, 2020. In the absence of a centralized training camp, all candidates for the national team were training in their clubs according to the plan presented by the head coach. Training and competition loads were monitored together with the national team coaches*. The results of volume and intensity of exercises were taken to assess the focus of the load. The wireless Polar system was used for individual heart rate control. We categorized the competitive load as mixed aerobic-anaerobic in the amount of 40 minutes per game. (Warm-up before the game and hitch after the game were not included in the volume of the competitive load).

* Control and fixing of training loads was carried out by the coaches of the national team of the Republic of Belarus Pavel Gabrinevsky and Dmitry Onachenko.

\section{RESEARCH METHODS}

Pedagogical observations, pedagogical control, expert assessment method, heart rate control with the Polar H7 (year of manufacture 2017). Polar H7 - heart rate sensor Compatible with iOS mobile device; iPhone 5. The sensor battery lasts 400 hours in Bluetooth Low Energy mode and when the transmission is switched on at a frequency of $5 \mathrm{kHz}$. Battery Type CR 2025. Sensor Size 34x65×10 mm, Weight $21 \mathrm{~g}$. Training plans analysis, methods of mathematical statistics. Calculation of the energy focuses of the loads according to Godik M. (1980). The direct load on the athlete's body in terms of heart rate was controlled during trainings and competitions. Training load was the main object of study. The volume and intensity of the load were recorded for its control and evaluation, according to the following indicators:

- The number of training and rest days in the microcycle.

- The number of one-time and two-time training classes per day in the microcycle.

- Total training duration (minutes).

The total assessment of the load volume 
gives only an overall picture. Local load indicators were used for more precise control:

1. Number of exercises repetitions.

2. Number of athletes participating in the exercise.

3. Playing space area where the exercise was performed.

4. Individual heart rate (HR) indicators.

\section{RESEARCH RESULTS}

The main characteristics of the studied hockey players of Belarus National indoor hockey team are shown below. Table 1 shows the average values of the characteristics of female European champions in 2020, depending on the playing position on the field.

Table 1. Characteristics of the studied hockey players of Belarus National indoor hockey team

\begin{tabular}{|c|c|c|c|c|}
\hline \multicolumn{2}{|c|}{ Characteristics } & Goalkeeper $(n=2)$ & Defender $(n=4)$ & Forward $(n=6)$ \\
\hline \multirow{3}{*}{$\begin{array}{l}\text { Age } \\
\text { (years) }\end{array}$} & M & 34 & 25.5 & 29.3 \\
\hline & $\sigma$ & 7.1 & 4.8 & 4.6 \\
\hline & $\mathrm{V}$ & $20.8 \%$ & $18.8 \%$ & $15.8 \%$ \\
\hline \multirow{3}{*}{$\begin{array}{l}\text { Height } \\
(\mathrm{sm} .)\end{array}$} & $\mathrm{M}$ & 166 & 162.2 & 166.1 \\
\hline & $\sigma$ & 5.6 & 7.4 & 1.2 \\
\hline & $\mathrm{V}$ & $3.4 \%$ & $4.7 \%$ & $0.7 \%$ \\
\hline \multirow{3}{*}{$\begin{array}{l}\text { Weight } \\
\text { (kg.) }\end{array}$} & $\mathrm{M}$ & 68 & 61.5 & 57.8 \\
\hline & $\widetilde{\sigma}$ & 5.6 & 12.3 & 19.7 \\
\hline & $\mathrm{V}$ & $8.3 \%$ & $20.0 \%$ & $7.0 \%$ \\
\hline \multirow{3}{*}{$\begin{array}{l}\text { Hockey experience } \\
\text { (years) }\end{array}$} & $\mathrm{M}$ & 22.5 & 12.3 & 19.7 \\
\hline & $\sigma$ & 4.9 & 4.3 & 4.0 \\
\hline & $\mathrm{V}$ & $22.0 \%$ & $35.5 \%$ & $20.5 \%$ \\
\hline
\end{tabular}

Training process of the women's national Indoor hockey team of Belarus is presented in detailed characteristics, graphs and diagrams reflecting the amount of training and competition load performed by the girls in the studied time range. The preparation and implementa- tion period consisted of 91 days ( 3 full months) and was divided into three Blocks: Accumulation Block (AB), Transforming Block (TB) and Implementation Block (IB). Table 2 shows the block structure of hockey player training and the characteristics of microcycles (MCC).

Table 2. The structure of the preparation of the women's national team of the Republic of Belarus for the European Indoor hockey Championship on January 24-26, 2020 in Minsk (Belarus) and the characteristics of MCC

\begin{tabular}{|c|c|c|c|c|c|c|c|c|c|c|c|}
\hline \multirow[b]{2}{*}{$\frac{v}{0}$} & \multirow[b]{2}{*}{ № } & \multirow[b]{2}{*}{ MCC (name) } & \multirow[b]{2}{*}{ MCC duration } & \multirow{2}{*}{ 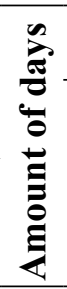 } & \multicolumn{5}{|c|}{ Characteristics of $\mathrm{MCC}$} & \multicolumn{2}{|c|}{$\begin{array}{l}\text { Where did the } \\
\text { players prepare }\end{array}$} \\
\hline & & & & & 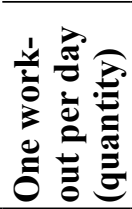 & 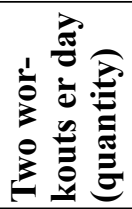 & 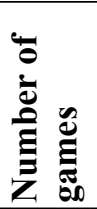 & 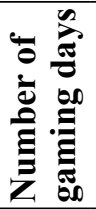 & 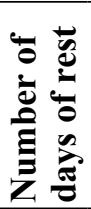 & 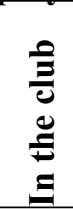 & 距 \\
\hline \multirow{5}{*}{$\mathrm{AB}$} & 1 & Preparatory & $28.10-5.11 .19$ & 9 & 8 & - & - & - & 1 & $\bar{X}$ & \multirow{5}{*}{$\mathrm{X}$} \\
\hline & 2 & Special-Preparatory & $6.11-11.11 .19$ & 6 & 3 & 2 & 4 & 2 & 1 & & \\
\hline & 3 & Competitive & $12.11-18.11 .19$ & 7 & 4 & 2 & 4 & 2 & 1 & $\mathrm{X}$ & \\
\hline & 4 & Shock microcycle & $19.11-28.11 .19$ & 10 & 9 & - & - & - & 1 & $X$ & \\
\hline & 5 & Recovery microcycle & 29.11-3.12.19 & 5 & 4 & & 2 & 2 & 1 & $\mathrm{X}$ & \\
\hline \multirow{4}{*}{ TB } & 1 & Special-Preparatory-1 & $4.12-9.12 .19$ & 6 & 2 & 3 & 6 & 3 & 1 & $\mathrm{X}$ & \multirow{4}{*}{$X$} \\
\hline & 2 & Special-Preparatory-2 & $10.12-16.12 .19$ & 7 & 3 & 3 & 6 & 3 & 1 & $X$ & \\
\hline & & Shock microcycle & $17.12-22.12 .19$ & 6 & - & 4 & - & - & 2 & & \\
\hline & 4 & Recovery microcycle & $23.12-31.12 .19$ & 9 & 5 & 1 & 4 & 3 & 3 & $X$ & \\
\hline \multirow{5}{*}{ IB } & 1 & Special-Preparatory & $1.01-11.01 .20$ & 11 & 7 & - & 8 & 2 & 4 & & $\mathrm{X}$ \\
\hline & 2 & Shock microcycle & $12.01-19.01 .20$ & 8 & - & 7 & 1 & 1 & - & & $\mathrm{X}$ \\
\hline & \multirow{2}{*}{\multicolumn{2}{|c|}{$\begin{array}{l}3 \text { pre-game microcycle } \\
\text { European Nations } \\
\text { Championships }\end{array}$}} & $20.01-23.01 .20$ & 4 & 1 & 3 & 3 & 3 & - & & $\mathrm{X}$ \\
\hline & & & $24.01-26.01 .20$ & 3 & - & 2 & 5 & 3 & - & & $X$ \\
\hline & & Total: & & 91 & 46 & 27 & 43 & 24 & 16 & & \\
\hline
\end{tabular}


The centralized gatherings of the National team amounted to $46.7 \%$ of the entire preparation period for the European Championship. Three blocks are presented in the training structure, in which the corresponding MCC consequentially alternate. Nine of $13 \mathrm{MCC}$ consisted of two workouts, or workout plus a game (or two games) per day. The distribution of rest days is noteworthy. Despite the different duration of the MCC, depending on the tasks to be solved only one day of rest was used in the MCC of the accumulation block (AB). In the transforming block (TU), the last shock and restorative MCC included 5 rest days. In the final implementation block (IB), only in the first special preparatory MCC 4 days of rest out of 11 training days were allocated. As for the shock and pre-game MCC along with the
European Championship itself, they were held without taking a rest! Recovery activities took place along with two training sessions and two games per day. During this period, 2 masseurs worked with the National team.

It is noteworthy that the coaching staff used a large number of games (friendly, test and official) in 10 of $112 \mathrm{MCC}$, which indicates the importance and dynamic stability of competitive training in all units. Totally, there were 38 games, of which only 10 were national Championship games.

The block system of Belarus hockey players training for the European Championship is confirmed by the graph of the average volume of training and competition load per day, presented in Figure 1.

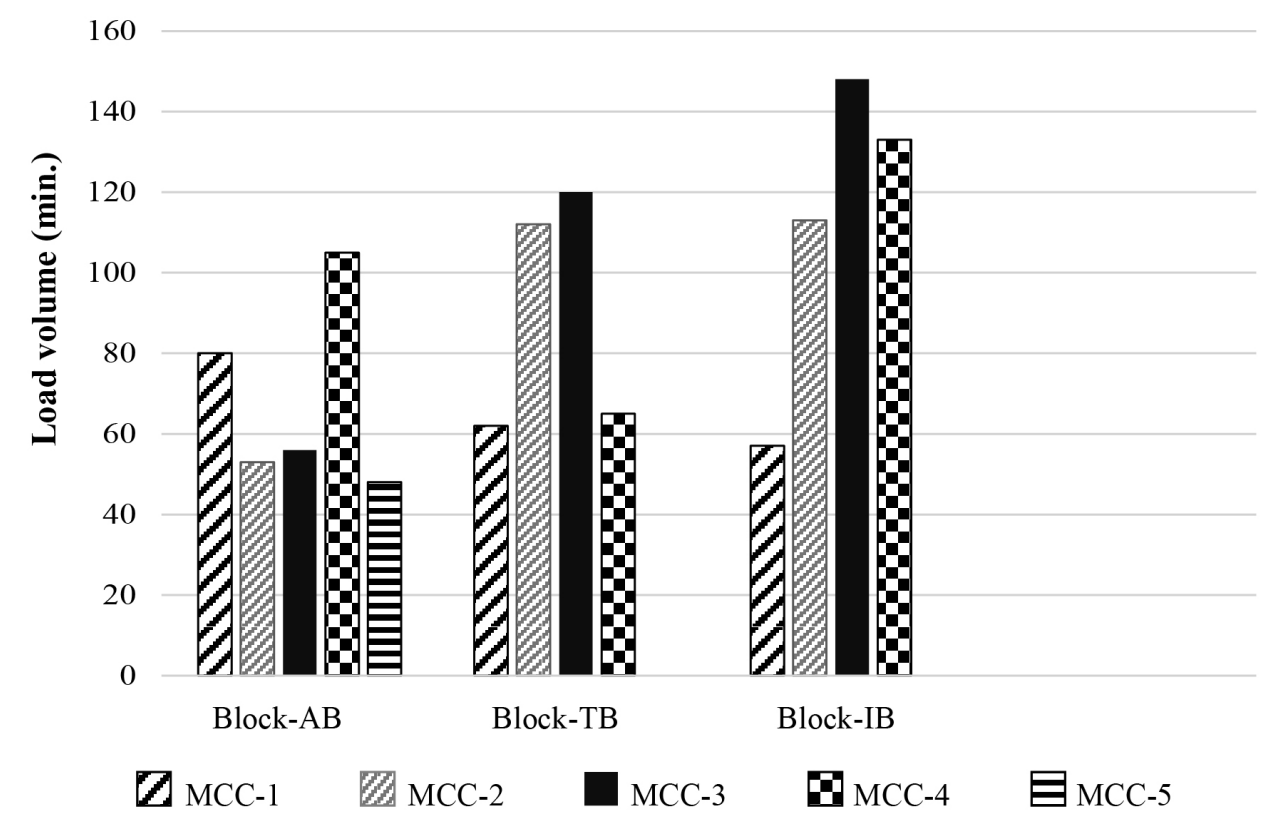

Figure 1. Average amount of training and competitive load per day

This indicator carries a conditional, but informational value. The diagram shows that the average amount of training load per day in each block was wave-like except the preparatory $\operatorname{MCC}(\mathrm{AB})$, the main volume of which consisted of aerobic exercises. This wave like character is due to a gradual increase at the beginning of the cycle, and a decrease at the end of the daily load volume. The volume of the average daily load from block to block was also gradually increasing from 79.9 minutes per day $(\mathrm{AB})$ to $84.1 \mathrm{~min}$ (TB) and $113.8 \mathrm{~min}$ in the rest block (IB).

The wave-like volume of the load corresponded to the periodicity and cyclicity which are the basic principles of sports training. The considered three-month stage of training and 
participating of the Belarus women's team in the European Championship was an integral part of the annual training cycle for summer hockey players, and effectively fit into the overall plan for preparing both the national team and club teams for the Olympic field hockey discipline competitions.

In our opinion, the analysis of the dynam- ics of distribution of loads of different energy focusing is significant. Table 3 presents the characteristics of the MCC and the distribution of training and competitive loads throughout them. We have classified training loads by their energy focusing by Professor Godik, M. (1980). Each of these loads corresponds to a certain combination of load components.

Table 3. Characteristics of training and competitive loads

\begin{tabular}{|c|c|c|c|c|c|c|c|c|c|c|}
\hline \multirow[b]{2}{*}{$\frac{v}{0}$} & \multirow[b]{2}{*}{$\underset{U}{U}$} & \multicolumn{4}{|c|}{$\begin{array}{l}\text { Energy orientation of the training } \\
\text { load in (min) }\end{array}$} & \multirow[b]{2}{*}{ 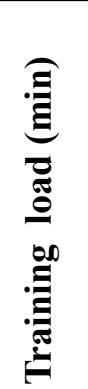 } & \multirow[b]{2}{*}{ 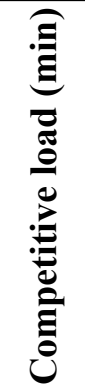 } & \multirow[b]{2}{*}{ 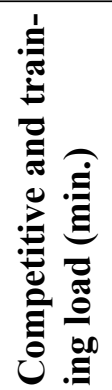 } & \multirow[b]{2}{*}{$\begin{array}{c}\text { AVERAGE } \\
\text { training and } \\
\text { competition } \\
\text { load per day } \\
\text { at the MCC } \\
\text { (min) }\end{array}$} & \multirow[b]{2}{*}{$\begin{array}{l}\text { AVERAGE } \\
\text { LOAD } \\
\text { per day in } \\
\text { BLOCK } \\
\text { (min) }\end{array}$} \\
\hline & & 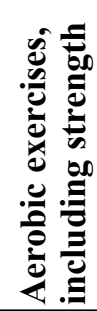 & 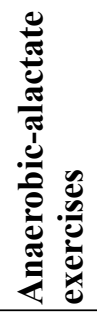 & 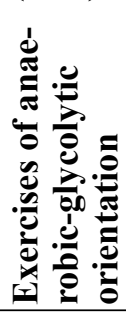 & 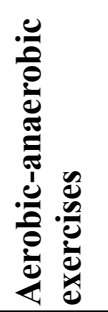 & & & & & \\
\hline \multirow{5}{*}{$\mathbf{A B}$} & 1 & 460 & 90 & 30 & 140 & 720 & & 720 & 80 & \multirow{5}{*}{79.7} \\
\hline & 2 & 80 & - & - & 80 & 160 & 160 & 320 & 53 & \\
\hline & 3 & 150 & 30 & 30 & 250 & 460 & 160 & 620 & 56 & \\
\hline & 4 & 260 & 90 & 90 & 610 & 1050 & - & 1050 & 105 & \\
\hline & 5 & 50 & - & - & 110 & 160 & 80 & 240 & 48 & \\
\hline \multirow{4}{*}{ TB } & 1 & 70 & - & - & 60 & 130 & 240 & 370 & 62 & \multirow{4}{*}{84.1} \\
\hline & 2 & 225 & - & 30 & 290 & 545 & 240 & 785 & 112 & \\
\hline & 3 & 160 & 40 & 40 & 480 & 720 & - & 720 & 120 & \\
\hline & 4 & 130 & - & - & 290 & 420 & 160 & 580 & 65 & \\
\hline \multirow{4}{*}{ IB } & 1 & 170 & - & - & 140 & 310 & 320 & 630 & 57 & \multirow{6}{*}{113.8} \\
\hline & 2 & 300 & 100 & 40 & 860 & 1300 & 40 & 1340 & 113 & \\
\hline & 3 & 180 & - & - & 290 & 470 & 120 & 590 & 148 & \\
\hline & 4 & 100 & - & - & 100 & 200 & 200 & 400 & 133 & \\
\hline \multicolumn{2}{|c|}{ Total: } & 2335 & 350 & 260 & 3700 & 6645 & 1720 & 8365 & & \\
\hline \multicolumn{2}{|c|}{$\%$} & 27.9 & 4.2 & 3.1 & 44.2 & 79.4 & 20.6 & 100 & & \\
\hline
\end{tabular}

Of interest is the analysis of the content of was one of the main means of the Belarusian training loads of various focusing in the struc- women's team players training. Its total volture of the MCC and especially the distribution ume amounted to 1720 minutes (43 games), of the competitive load. The competitive load which takes $20.6 \%$ of the total load (Figure 2).

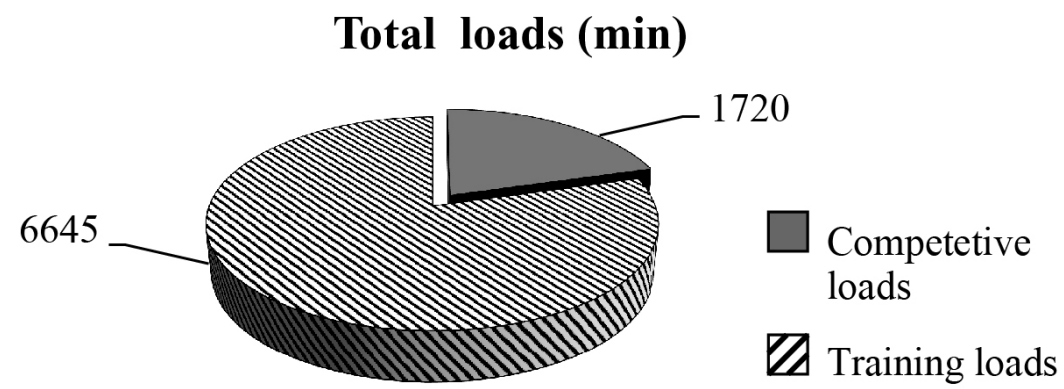

Figure 2. The ratio and distribution of total loads during the women's national Belarus team training for the European Indoor Hockey Championship 
In training loads, exercises of a mixed (aerobic-anaerobic) orientation-44.2\% prevailed (Figure 3). These are various technical and tactical exercises performed in variable speed mode. The aerobic load (warm-up and stopping means, tactical developments, strength exercises) amounted to $28 \%$. The percentage of non-specific anaerobic loads was $7.3 \%$, of which anaerobic-alactate, speed-force orientation was $4.2 \%$ (350 minutes for the entire period) and anaerobic-glycolytic, aimed at developing speed endurance - 3.1\% (260 minutes).

\section{Energy orientation of the training load (min)}

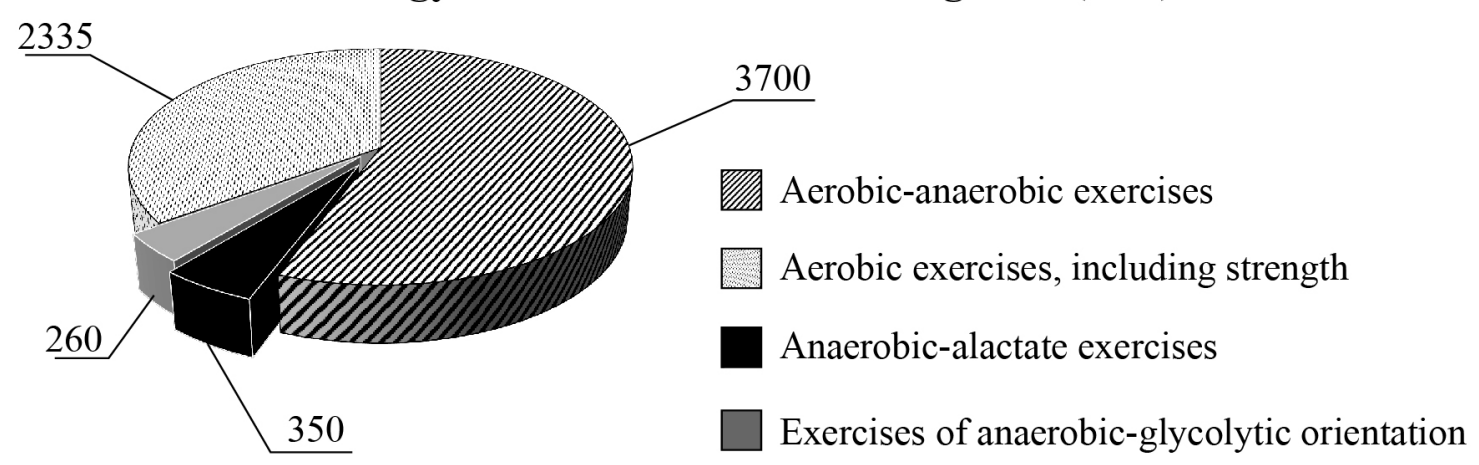

Figure 3. The ratio and distribution of energy orientation training loads

It is important to note the dynamics of such loads was three times less, 110 and 140 anaerobic exercise. The bulk of high-speed minutes, respectively. non-specific work (360 min.) fell on the first

Figure 4 shows the dynamics of loads of Accumulating Block. In the Transformation different energy focusing. and Implementation Blocks, the volume of

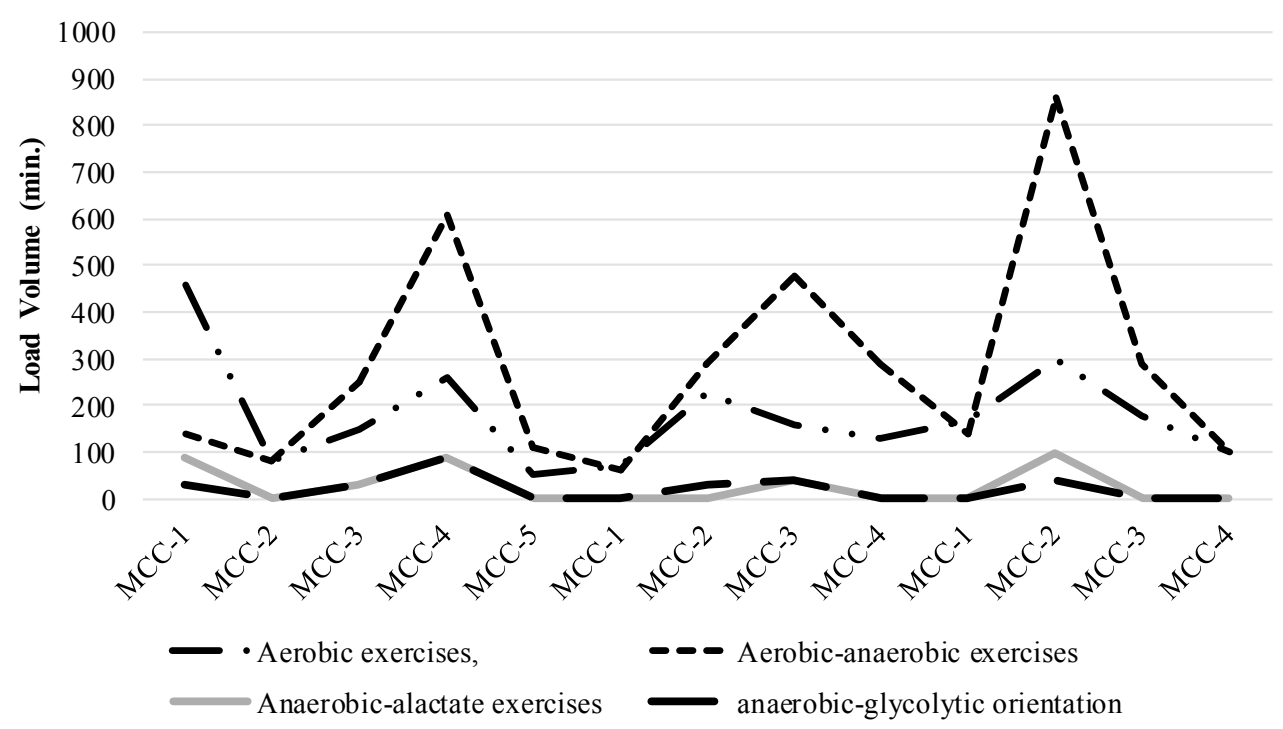

Figure 4. Dynamics of various energy focusing loads at every $M M C$

All stages of preparation are clearly visible. The maximum volumes of mixed loads of aerobic-anaerobic orientation correspond to Shock MCC: in the Accumulation Block, their volume was 610 minutes, 480 minutes in the Transformational one, and 860 minutes 
in the IB. This is the main type of load, which includes specialized exercises of technical and tactical orientation, whose share in the overall structure of training was $44.2 \%$, and in the structure of training loads was more than a half - 56\% (Figure 3). Nonspecific speed-strength training and speed endurance exercises were used mainly in Shock MCC (AB-180 min.; TB-80min. and IB-140min.) It was a combination of non-specific loads of anaerobic orientation with specialized exercises of technical and tactical orientation that showed to be the shock balanced and the most effective structure for the National team training.

Assessing the structure of the daily training process for the national team players, it was interesting to compare the dependence of the average training time per day with the training and competitive loads of various energy orientation. When using the mathematical method for calculating the Pearson correlation coefficient between aerobic energy load indicators and the amount of training load per day, the correlation coefficient is +0.28 ; with mixed load +0.27 ; with anaerobic +0.24 ; with competitive it is negative - 0.28. Thus, to a greater extent, the amount of training load per day depends on aerobic and mixed (but not competitive) loads. Competitive loads are represented by games of international tournaments at certain stages of training, including the first accumulative block, and test games on the eve of the European Championship in the Implementation Block. The structure of competitive training is presented in Figure 5.

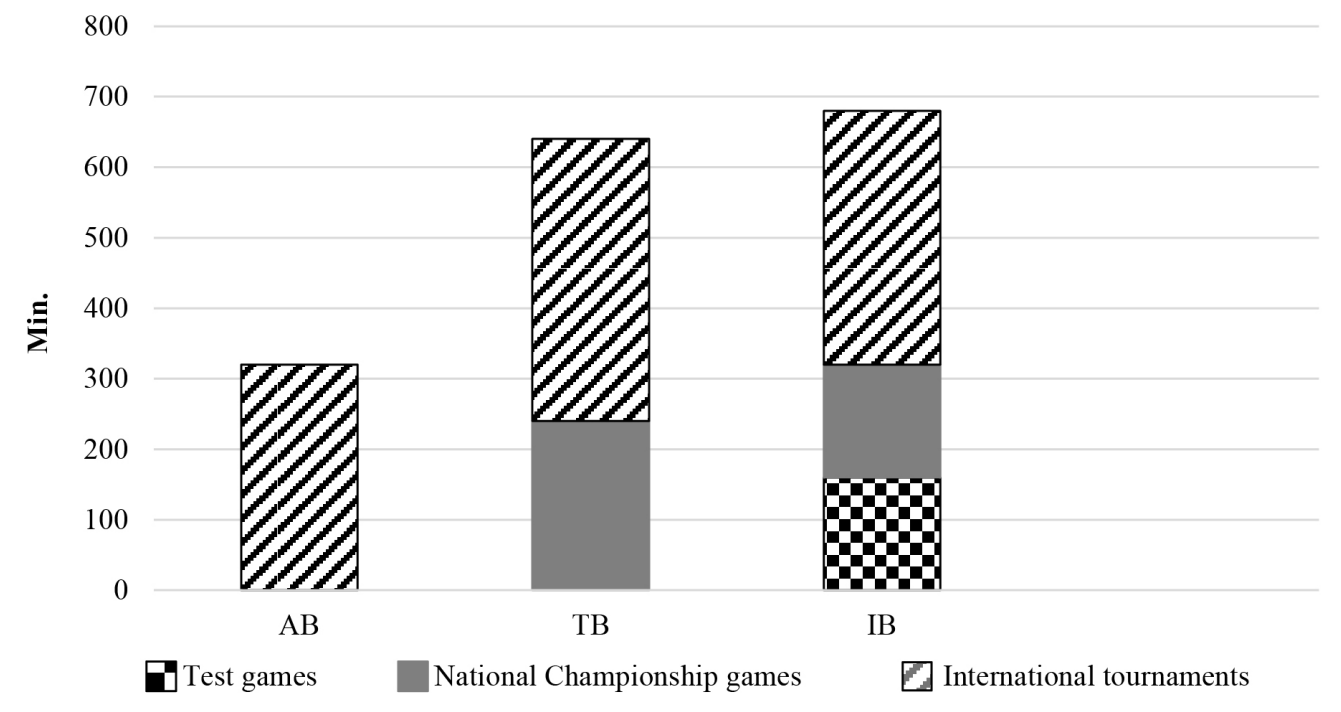

Figure 5. The structure of the competitive training of the women's national team of the Republic of Belarus getting ready for the European Championship

Despite the negative correlation between the volume of daily training loads and competitive loads, we separated the latter in a standalone schedule. From December 4 to January 23, the Belarus national team players played 31 games plus 5 games of the European Championship itself. Of these, they played
10 games as part of club teams at the national championship games, 21 games as part of the national team (international tournaments in Poland, Russia and Austria) and 4 test games on the eve of the continental championship in Minsk.

An analysis of the Republic of Belarus 
women's national team training structure is presented from the perspective of a block system of periodization. Thus, we can state that the polycyclic principle of building the training process in game sports is currently approved. The women's national team of the Republic of Belarus performance at the European Championship exceeded expectations. The team, led by Dutch specialist Herman Kruis, became the champion of Europe for the first time in its history.

\section{CONCLUSIONS}

1. The proposed training structure for the women's national team of the Republic of Belarus can be considered as a model of preparation for the European Championships and World Cups.

2. The polycyclic training process building based on the block system is an effective means of preparation in the Indoor Hockey as a game sport.

3. The general Indoor Hockey teams training plan (as a game sport training) for important tournaments such as the European Championship and the World Cup should be considered from two perspectives: a. Training process planning; b. Competitive training planning.

4. The combination of non-specific loads of anaerobic orientation with specialized technical and tactical exercises has formed the basis of shock MCC of accumulative and implementation blocks and effectively fit into the national team training structure for the European Championship.

5. The average amount of training load per day in each block is wave-like. This is due to gradual increase at the beginning of the cycle, reaching maximum in the middle, and decreasing of the daily load volume at the end of the cycle.

\section{REFERENCES}

Antonov A., Dimitrieska, T. (2013). Normativi za planirane, control i otcenka na sportnata podgotovka po hockey, NSA Pres, Sofia

Antonov, A. (2014a). Model characteristics of hockey sport preparation in Bulgaria, 17 th Symposium for Sport and Physical Education of Youth, Federation of Sports Pedagogues of the Republic of Macedonia, Ohrid, Activities in Physical Education and Sport, Vol. 4, No. 2, pp. $139-141$

Antonov, A. (2014b). Modelling the system of national field hockey competitions in Bulgaria, Sports Physical Activity and Health, Bratislava

Bondarchuk, A. (1986). Athlete Training, Kiiv, Healthy I, 160p.

Chavdarov, S., Antonov A. (2017). Structure and model of annual sport training of elite women hockey players in Bulgaria and Italy, Physical Education, Sport, Kinesitherapy Research Journal /PESKRJ/, 2(1), Art.4, pp.1827

Godik, M. (1980). Control of training and competitive loads, Moscow: FIS, pp. 135

Issurin, V. (2012). Block periodization of sports training: a monograph. - Moscow, Soviet Sport, pp. 282

Issurin, V. (2019). Training of athletes of the XXI century: the scientific basis and the construction of training, 2nd ed. stereotypical, Moscow, Sport.

Kelly, D.M, Strudwick, A.J., Atkinson, G., Drust, B. \& Gregson, W. (2020). Quantification of training and match-load distribution across a season in elite English Premier League soccer players, Science and Medicine in Football, 4:1, 59-67, DOI: 10.1080/24733938.2019.1651934

Kostyukevich, V. (2011). Simulation of the training process in field hockey. Monograph, Vinnitsa, Glider Firm LLC, pp.736

Lythe, J. (2008). The physical demands of elite men's field hockey and the effects of 
differing substitution methods on the physical and technical outputs of strikers during match play. Division of Sport and Recreation, Auckland University of Technology, pp.160

Perrotta, A.S., Held, N.J. \& Warburton, D.E.R. (2017). Examination of internal training load parameters during the selection, preparation and competition phases of a mesocycle in elite field hockey players, International Journal of Performance Analysisin Sport,

\section{$17: 5,813-821$}

Touretski, G. (1998). Preparation of sprint events, ASCTA Convention / Kanberra: Australian Institute of Sport.

Verkhoshansky, Yu. (1985). Programming and organization of the training process, Moscow, FiS, 176p.

Zelentsov, A. (1985). Modeling training in football, Kiiv, Healthy I, pp.136

Corresponding author:

Igor Shishkov

Moscow State Academy of Physical Culture

Football \& hockey department Shosseynaya 33, Malahovka, Moscow region 140033

Russian Federation E-mail: igorshiskov8@gmail.com 